\title{
Nanocomposite "Xuan Paper” Made from Ultralong Hydroxyapatite Nanowires and Cellulose Fibers and Its Anti-mildew Properties
}

\author{
SHAO Yueting ${ }^{1,2}$, ZHU Yingjie ${ }^{1,2}$, DONG Liying ${ }^{1}$, CAI Anyong ${ }^{1,2}$
}

(1. Shanghai Institute of Ceramics, Chinese Academy of Sciences, Shanghai 200050, China; 2. Center of Materials Science and Optoelectronics Engineering, University of Chinese Academy of Sciences, Beijing 100049, China)

\begin{abstract}
Xuan paper is an indispensable carrier for Chinese calligraphy and painting works. It has won the reputation of "the King of Paper" because of its superior durability and anti-mildew performance. Xuan paper was inscribed on the Representative List of the Intangible Cultural Heritage of Humanity by the Educational, Scientific and Cultural Organization of the United Nations in 2009. In this study, we developed a new type of nanocomposite "Xuan paper" made from ultralong hydroxyapatite nanowires and cellulose fibers with excellent anti-mildew performance. The whiteness of the as-prepared nanocomposite "Xuan paper" with HAP weight ratio of $25 \%$ is $76.1 \%$, which is higher than that of the commercial unprocessed Xuan paper $(71.9 \%)$ or the commercial processed Xuan paper (70.3\%). The nanocomposite "Xuan paper" has superior performance in inhibiting the growth of three kinds of moulds (Chaetomium globosum, Trichoderma viride (long branch) and Aspergillus niger) compared with the blank control and commercial Xuan paper. During the incubation process, the mildew grows on the surface of the traditional Xuan paper, however, no obvious growth of mildew is observed on the surface of the nanocomposite "Xuan paper". It is expected that the nanocomposite "Xuan paper" is favorable for its long-term safe preservation and application in calligraphy and painting arts.
\end{abstract}

Key words: Xuan paper; hydroxyapatite; nanowire; anti-mildew

Paper has provided an important foundation for the spread of culture and knowledge and greatly contributed to human civilization. Among different kinds of paper, Xuan paper was first made in ancient China and used especially for Chinese calligraphy and paintings ${ }^{[1-2]}$. However, Xuan paper is made from organic cellulose fibers, it is easily affected by various internal and external factors during the long-term preservation process, causing the mildew mold on the paper. Cellulose fibers can be degraded by the mildew, resulting in deteriorating properties or even destroying of the Xuan paper $^{[3]}$.

Based on the problems facing the traditional Xuan paper, exploring new type of Xuan paper based on inorganic materials has become an important research topic. Hydroxyapatite (HAP, $\left.\mathrm{Ca}_{10}\left(\mathrm{PO}_{4}\right)_{6}(\mathrm{OH})_{2}\right)$ is a natural mineral and the main inorganic component of vertebrate bones and teeth, and has excellent biocompatibility and biological activity ${ }^{[4-7]}$. HAP biomaterials have various applications in biomedical fields, such as drug delivery, protein adsorption and release, bone defect repair, and bio-imaging $^{[8-11]}$. Ultralong HAP nanowires are an ideal material for making paper because it presents excellent biocompatibility, environmental friendliness, and high whiteness ${ }^{[12]}$. Zhu research group ${ }^{[12-15]}$ developed the calcium oleate precursor solvothermal/hydrothermal method to prepare ultralong HAP nanowires. They ${ }^{[12,15-19]}$ also reported a new kind of fire-resistant inorganic paper based on ultralong HAP nanowires. Ultralong HAP nanowires as an inorganic material cannot provide nutrients for the growth of the mildew. Therefore, Ultralong HAP nanowires are ideal raw material for making the highperformance "Xuan paper"[20]. Herein, we report a new kind of nanocomposite "Xuan paper" with excellent antimildew performance made from ultralong hydroxyapatite (HAP) nanowires and plant cellulose fibers.

Received date: 2020-02-23; Revised date: 2020-03-16; Published online: 2020-03-20

Foundation item: National Natural Science Foundation of China $(21875277,51702342)$

Biography: SHAO Yueting (1995-), female, Master. E-mail: shaoyueting95@126.com 郡悦婷(1995-)，女，硕士. E-mail: shaoyueting95@126.com

Corresponding author: ZHU Yingjie, professor. E-mail: y.j.zhu@mail.sic.ac.cn; DONG Liying, assistant professor. E-mail: lydong@mail. sic.ac.cn 朱英杰, 研究员. E-mail: y.j.zhu@mail.sic.ac.cn; 董丽颖, 助理研究员. E-mail: lydong@mail.sic.ac.cn 


\section{Experimental}

\subsection{Materials}

Calcium chloride $\left(\mathrm{CaCl}_{2}\right)$, sodium dihydrogen phosphate dihydrate $\left(\mathrm{NaH}_{2} \mathrm{PO}_{4} \cdot 2 \mathrm{H}_{2} \mathrm{O}\right)$, sodium hydroxide $(\mathrm{NaOH})$, sodium oleate and rose bengal medium were purchased from Sinopharm Chemical Reagent Co., Ltd. Absolute ethanol was purchased from Shanghai Lingfeng Chemical Reagent Co., Ltd. The commercial unprocessed Xuan paper and processed Xuan paper were obtained from China Xuan paper Co., Ltd. All chemicals were used as received without further purification. Deionized water was used in all related experiments. Spore suspensions of Chaetomium globosum, Trichoderma viride (long branch) and Aspergillus niger were purchased commercially. The concentration of spores was $1 \times 10^{6} \mathrm{CFU} / \mathrm{mL}$.

\subsection{Preparation of ultralong HAP nanowires}

Ultralong HAP nanowires were synthesized by the calcium oleate precursor hydrothermal method previously reported by our research group ${ }^{[15]}$. This synthetic method can be used to prepare ultralong HAP nanowires with lengths of several hundred micrometers and with ultrahigh aspect ratios, which has obvious advantages compared with other methods which can usually prepare short HAP nanowires with lengths less than $10 \mu \mathrm{m}^{[21-30]}$. In brief, $400.0 \mathrm{~g}$ of sodium oleate were dissolved in $4 \mathrm{~L}$ of deionized water, and an aqueous solution $(1.5 \mathrm{~L})$ containing $\mathrm{CaCl}_{2}$ (44.0 g) was added to the above aqueous solution. $1.5 \mathrm{~L}$ of aqueous solution containing $\mathrm{NaH}_{2} \mathrm{PO}_{4} \cdot 2 \mathrm{H}_{2} \mathrm{O}$ $(56.0 \mathrm{~g})$ were added to the above suspension under stirring Finally, the reaction mixture was transferred to a $10 \mathrm{~L}$ stainless steel autoclave reactor, sealed, heated to $200{ }^{\circ} \mathrm{C}$, and kept at $200{ }^{\circ} \mathrm{C}$ for $36 \mathrm{~h}$. The product was washed with absolute ethanol and deionized water three times, respectively.

\subsection{Preparation of the nanocomposite "Xuan paper”}

The commercial unprocessed Xuan paper was cut into scraps and added into a container with $1.5 \mathrm{~L}$ of deionized water under stirring for $30 \mathrm{~min}$. The paper pulp was put into an ultrasonic machine for $15 \mathrm{~min}$ to disperse homogeneously. Then, an aqueous suspension containing ultralong HAP nanowires was added into the above aqueous suspension under stirring. The weight ratio of ultralong HAP nanowires in the nanocomposite "Xuan paper" was $25 \mathrm{wt} \%$, and the total dry weight of ultralong HAP nanowires and cellulose fibers was $2.000 \mathrm{~g}$. The resulting aqueous suspension was filtered under vacuum in a paper machine to form the wet paper. The obtained wet paper was pressed under a pressure of $4 \mathrm{MPa}$ and dried at $105{ }^{\circ} \mathrm{C}$ for $3 \mathrm{~min}$, and the nanocomposite "Xuan paper" was obtained.

\subsection{Anti-mildew performance tests}

\subsubsection{Preparation of bengal red medium}

Deionized water was added to the rose bengal medium according to the formula, and heated under stirring till boiling, then placed in several $150 \mathrm{~mL}$ conical flasks. The conical flasks were wrapped with the kraft paper and sealing film, then sterilized in high-pressure steam at $121{ }^{\circ} \mathrm{C}$ for $20 \mathrm{~min}$. When the medium was cooled to $60{ }^{\circ} \mathrm{C}$, the plates were prepared in accordance with the aseptic procedure in the ultra-clean bench. Finally, they were tested for fungus-free growth at $28{ }^{\circ} \mathrm{C}$ for $48 \mathrm{~h}$.

\subsubsection{Preparation of bengal red medium containing spores}

Group A: a spore suspension with a concentration of $1 \times 10^{5} \mathrm{CFU} / \mathrm{mL}$ was prepared. A spore suspension with a volume of $100 \mu \mathrm{L}$ was put and absorbed on the surface of the bengal red solid medium.

Group B: a spore suspension with a concentration of $1 \times 10^{5} \mathrm{CFU} / \mathrm{mL}$ was prepared. During the preparation of the bengal red medium, after the medium was sterilized in high-pressure steam and cooled to $40{ }^{\circ} \mathrm{C}$, a spore suspension $(5 \mathrm{~mL})$ was added into $500 \mathrm{~mL}$ bengal red liquid medium, then, the resulting mixture was put onto culture plates to be solidified.

The as-prepared nanocomposite "Xuan paper" sheets with different HAP/cellulose weight ratios $(15 \%, 25 \%$, $35 \%$ and $100 \%$ ) were sterilized by dry heat at $105{ }^{\circ} \mathrm{C}$ for $48 \mathrm{~h}$, then they were cut into square pieces with sizes of $4 \mathrm{~cm} \times 4 \mathrm{~cm}$, were laid flat at the center of the as-prepared bengal red solid medium containing spores. In addition, the blank control group and commercial traditional unprocessed Xuan paper was also adopted for comparison. All samples were placed in a constant temperature and humidity incubator at $28{ }^{\circ} \mathrm{C}$ with a relative humidity of $90 \%$. The whole experimental process was performed in the ultra-clean bench. To ensure the data repeatability, at least three parallel tests were carried out for each measurement.

\subsubsection{Anti-mildew performance without culture medium}

The as-prepared nanocomposite "Xuan paper" sheets with different HAP/cellulose weight ratios (15\%, 25\%, $35 \%$ and $100 \%$ ) and commercial traditional unprocessed Xuan paper were sterilized by dry heat at $105{ }^{\circ} \mathrm{C}$ for $48 \mathrm{~h}$, then they were cut into square pieces with sizes of $2 \mathrm{~cm} \times$ $2 \mathrm{~cm}$, and all put into blank petri dishes. Then, the spore suspension $(100 \mu \mathrm{L})$ was put onto the surface of the paper. Afterwards, the petri dishes were sealed and placed upside down in a constant temperature and humidity incubator at $28{ }^{\circ} \mathrm{C}$ with a relative humidity of $90 \%$. 


\section{Results and discussion}

Fig. 1 shows SEM images of the commercial traditional unprocessed Xuan paper, the as-prepared new type of nanocomposite "Xuan paper" with a HAP weight ratio of $25 \%$, and ultralong HAP nanowires. Fig. 1(a,b) shows the porous structure of the commercial traditional Xuan paper formed by plant cellulose fibers. There are many pores among cellulose fibers with sizes in the micrometer scale. Ultralong HAP nanowires are approximately $10 \mathrm{~nm}$ in diameter and hundreds of microns in length, which are consistent with previous report ${ }^{[15]}$, and they intertwine with each other to form small pores (Fig. 1(c, d)). SEM images of the as-prepared nanocomposite "Xuan paper" based on ultralong HAP nanowires and cellulose fibers with HAP weight ratio of $25 \%$ indicate that ultralong HAP nanowires and cellulose fibers interweave with each other to form a porous networked structure ${ }^{[18]}$, as shown in Fig. 1(e, f).

Fig. 2(a) shows the XRD patterns of the commercial traditional unprocessed Xuan paper, the as-prepared new type of nanocomposite "Xuan paper" with a HAP weight ratio of $25 \%$, and ultralong HAP nanowires. The diffraction peaks at $2 \theta=21.8^{\circ}, 29.0^{\circ}, 31.8^{\circ}, 32.9^{\circ}, 39.8^{\circ}, 48.6^{\circ}$, $50.5^{\circ}, 51.3^{\circ}$ correspond to the (200), (210), (211), (300), (310), (320), (321), and (410) crystal planes of hydroxyapatite (JCPDS 09-0432), respectively ${ }^{[20]}$. The as-prepared new type of nanocomposite "Xuan paper" has similar diffraction peaks to those of ultralong HAP nanowires, but there are two additional broad diffraction peaks at around $2 \theta=15^{\circ}$ and $24^{\circ}$ which are characteristic peaks of the traditional Xuan paper, indicating that the as-prepared new type of nanocomposite "Xuan paper" is composed of ultralong HAP nanowires and plant cellulose fibers ${ }^{[16,20]}$. Fig. 2(b) shows FTIR spectra of the commercial traditional unprocessed Xuan paper, the nanocomposite "Xuan paper" with a HAP weight ratio of $25 \%$, and ultralong HAP nanowires. The characteristic bands of $\mathrm{PO}_{4}{ }^{3-}$ ions locate around 1097, 1029, 603 and $561 \mathrm{~cm}^{-1}$, and the absorption peak at around $3571 \mathrm{~cm}^{-1}$ is derived from the hydroxyl group $(-\mathrm{OH})$ in ultralong HAP nanowires ${ }^{[31-34]}$. In addition, the absorption peak at $2920 \mathrm{~cm}^{-1}$ is derived from $\mathrm{C}-\mathrm{H}$ in cellulose fibers.

The whiteness of the as-prepared nanocomposite "Xuan paper" is enhanced compared with that of the commercial unprocessed Xuan paper or commercial processed Xuan paper (Fig. 3(a)). The as-prepared pure HAP nanowire paper composed of exclusive ultralong HAP nanowires has a high whiteness of $89.1 \%$, which is consistent with our previous report ${ }^{[16]}$. The experimental results indicate that the whiteness of the nanocomposite "Xuan paper" increases with the increasing HAP weight ratio. The whiteness of the nanocomposite "Xuan paper" with a HAP weight ratio of $25 \%$ is $76.1 \%$, which is higher than that of the commercial unprocessed Xuan paper $(71.9 \%)$ or the commercial processed Xuan paper $(70.3 \%)$. However, the tensile strength of the nanocomposite "Xuan paper" decreases with increasing HAP weight ratio.

The as-prepared nanocomposite "Xuan paper" sheets with different HAP weight ratios $(0,10 \%, 25 \%, 40 \%$ and $100 \%$ ) were cut into paper pieces with a width of $15 \mathrm{~mm}$ and a length of $250 \mathrm{~mm}$, one end of the paper was clamped to the paper holder, and the other end was vertically
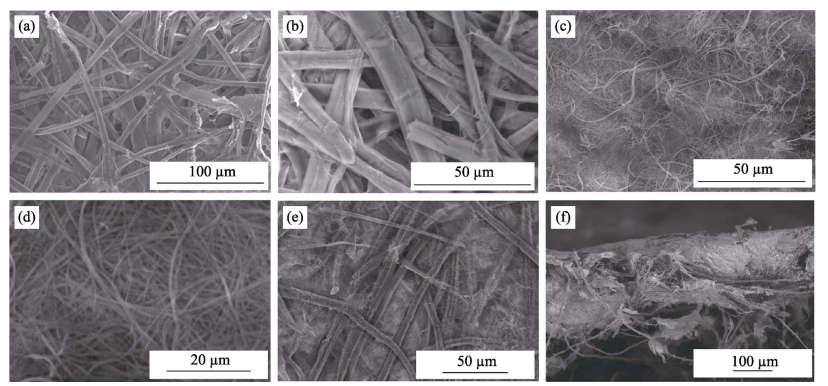

Fig. 1 SEM images of $(a, b)$ the commercial unprocessed Xuan paper, (c, d) ultralong HAP nanowires, $(e, f)$ the as-prepared new type of nanocomposite "Xuan paper" based on ultralong HAP nanowires and cellulose fibers with HAP weight ratio of $25 \%$
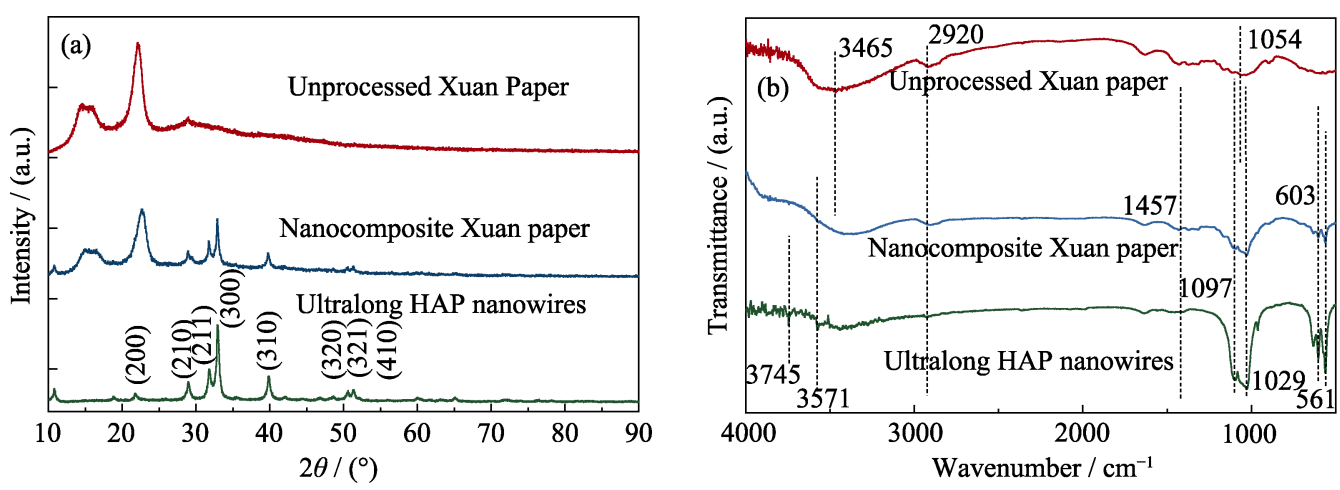

Fig. 2 XRD patterns (a) and FT-IR spectra (b) of the commercial unprocessed Xuan paper, the as-prepared new type of nanocomposite "Xuan paper" with HAP weight ratio of $25 \%$, and ultralong HAP nanowires 
inserted into deionized water for a depth of $5 \mathrm{~mm}$ at a temperature of $(23 \pm 1){ }^{\circ} \mathrm{C}$. The rising height of water or ink level was measured after $5 \mathrm{~min}$, and the arithmetic mean value was reported (Fig. 3(b)). It has been found that the height of water and ink level gradually decreases with the increasing HAP weight ratio. The experimental results indicate that the water absorption capacity of ultralong HAP nanowires is much lower than that of cellulose fibers. It was reported that the filling chemical potential for ultra-small pores is the sum of adsorption energy and capillary energy. For ultra-small pores, these two terms are equally important but the capillarity is dependent on the pore size ${ }^{[35]}$. Under the same conditions, cellulose fibers will absorb more water. Xuan paper has a porous structure and strong moisture absorption ability, leading to the growth of mildew.

Experiments were designed to test the ability of different kinds of paper samples for inhibiting the mildew growth. The as-prepared nanocomposite "Xuan paper" sheets with different HAP weight ratios (15\%, 25\%, 35\% and $100 \%$ ) were selected for the tests. In addition, the

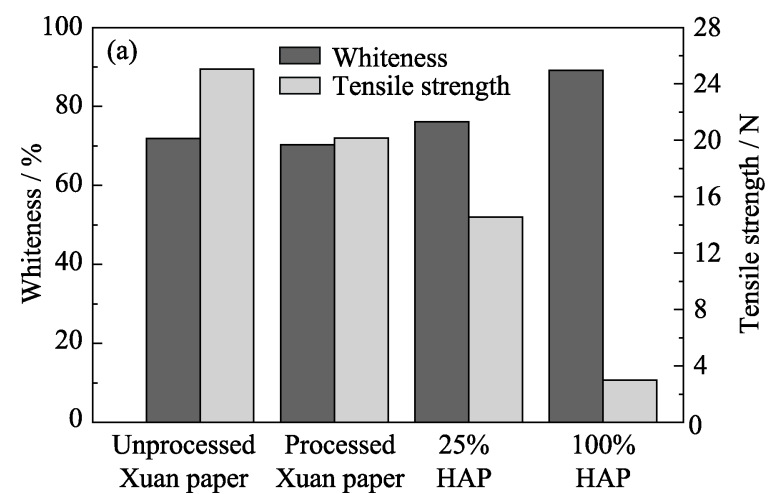

commercial unprocessed Xuan paper and processed Xuan paper were used as the control samples. The experimental results are clearly shown in the digital images in Fig. 4. In the presence of three different kinds of mildew (Chaetomium globosum, Trichoderma viride (long branch), Aspergillus niger), the as-prepared nanocomposite "Xuan paper" sheets exhibit the better inhibition ability to the growth of mildew compared with the blank control and the commercial Xuan paper. The average growth rates of three different kinds of mildew on the surface of the nanocomposite "Xuan paper" sheets containing ultralong hydroxyapatite nanowires are obviously lower, and decrease with the increasing HAP weight ratio. The inhibition effect is most obvious for long branch Trichoderma viride. The as-prepared nanocomposite "Xuan paper" sheets with different HAP ratios exhibit a better performance for inhibition of the mildew compared with the traditional Xuan paper. This result may be explained that organic cellulose fibers can provide nutrients for the growth of mildew ${ }^{[16]}$.

Figs. 4 and 5 show the digital images of six different

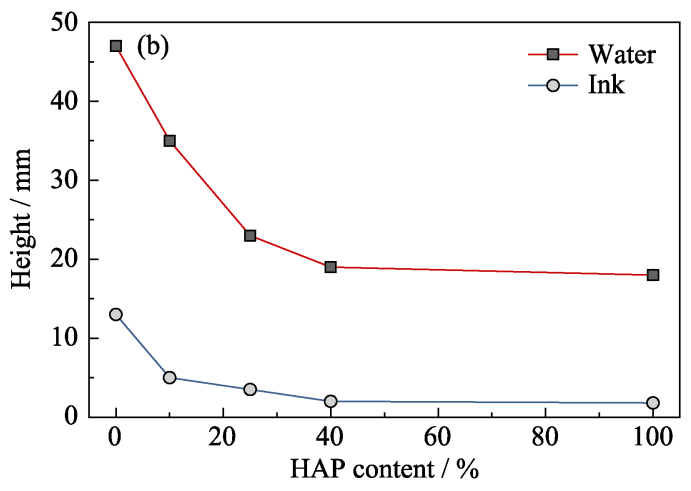

Fig. 3 (a) Whiteness and tensile strength of the commercial unprocessed Xuan paper, the as-prepared new type of nanocomposite "Xuan paper" with HAP weight ratio of $25 \%$, and ultralong HAP nanowires; (b) The diffusion heights of the as-prepared new type of nanocomposite "Xuan paper" with HAP weight ratios ranging from 0 to $100 \%$, the paper as put vertically in deionized water and ink for absorption time of $5 \mathrm{~min}$. The diffusion height was measured from the surface of water or ink upward
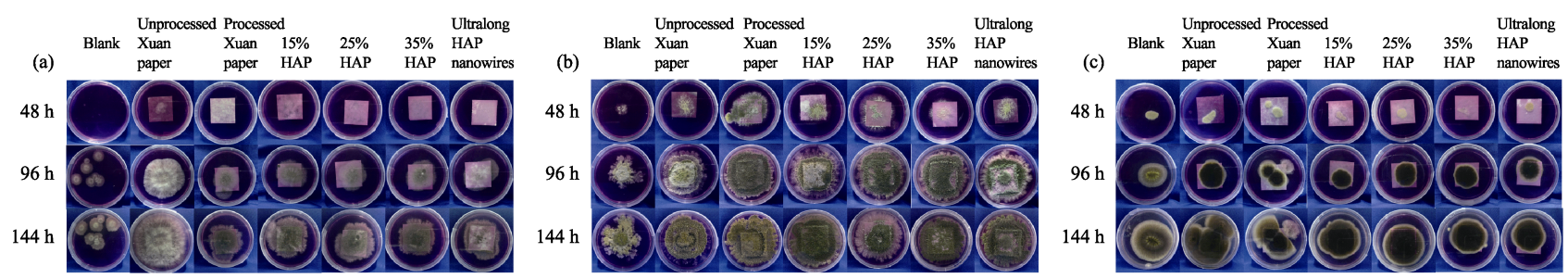

Fig. 4 Digital images of six different kinds of paper samples and blank group after incubation with the group A for different time (a) Chaetomium globosum; (b) Trichoderma viride (long branch); (c) Aspergillus niger
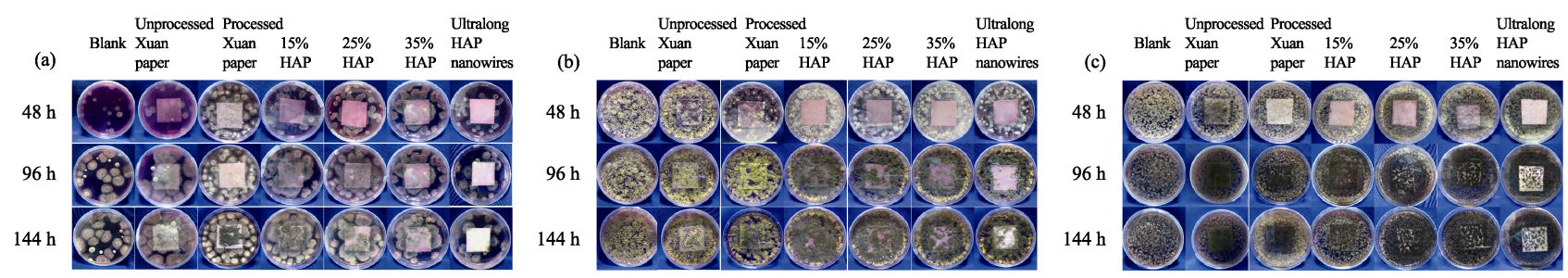

Fig. 5 Digital images of six different kinds of paper samples and blank group after incubation with the group B for different time (a) Chaetomium globosum; (b) Trichoderma viride (long branch); (c) Aspergillus niger 

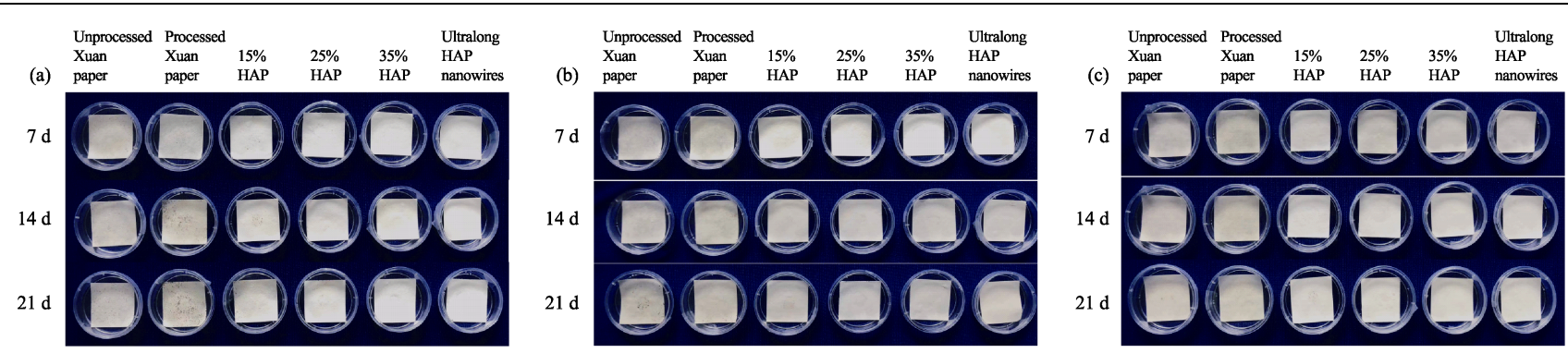

Fig. 6 Digital images of six different kinds of paper samples after incubation without culture medium group for different time which is closer to the usual Xuan paper preservation conditions

(a) Chaetomium globosum; (b) Trichoderma viride (long branch); (c) Aspergillus niger

kinds of paper samples and blank group after incubation for different times with the group A and the group B, respectively. The growth area and mildew colonies on different paper samples were obviously different, and the mycelium penetration through the paper was also different. The traditional Xuan paper was almost completely penetrated by the hypha, and the surface was covered with the mildew. However, the surface of the as-prepared nanocomposite "Xuan paper" sheets with different HAP weight ratios was obviously different. Hydroxyapatite has good anti- mildew performance and can effectively inhibit the growth of the mildew. The as-prepared nanocomposite "Xuan paper" has superior anti-mildew properties compared with the traditional Xuan paper. Similar experimental results are also observed in the experiment without culture medium (Fig. 6). During the incubation process for 7 to $21 \mathrm{~d}$ in a constant temperature and humidity chamber, the mildew grows on the surface of the traditional Xuan paper, however, no obvious growth of mildew is observed on the surface of the as-prepared nanocomposite "Xuan paper". It is worth noting that this experimental condition is actually closer to the usual Xuan paper preservation conditions.

\section{Conclusion}

In this work, we have developed a new type of nanocomposite Xuan paper made from ultralong hydroxyapatite nanowires and plant cellulose fibers. Compared with the traditional Xuan paper, the most outstanding feature of the as-prepared nanocomposite "Xuan paper" is that it can retain the basic properties of the traditional Xuan paper and has an enhanced anti-mildew performance. The as-prepared nanocomposite "Xuan paper" has excellent performance in inhibiting the adhesion, spread and growth of three kinds of moulds (Chaetomium globosum, Trichoderma longibrachiatum and Aspergillus niger), which is promising for the application in calligraphy and painting arts for their long-term safe preservation.

\section{References:}

[1] LIU R Q. The human heritage of the national treasure Xuan paper. Encyclopedic Knowledge, 2010, 2: 24-27.

[2] HU W J, ZHAO D S. Analysis of the life characteristics of Xuan paper. China Pulp \& Paper Industry, 2013, 34: 74-76.

[3] ZYSKA B. Fungi isolated from library materials: a review of the literature. International Biodeterioration \& Biodegradation, 1997, 40(1): $43-51$.

[4] HUI J F, Wang X. Hydroxyapatite nanocrystals: colloidal chemistry, assembly and their biological applications. Inorganic Chemistry Frontiers, 2014, 1(3): 215-225.

[5] ŠUPOVÁ M. Substituted hydroxyapatites for biomedical applications: a review. Ceramics International, 2015, 41(8): 9203-9231.

[6] HAIDER A, HAIDER S, HAN S S, et al. Recent advances in the synthesis, functionalization and biomedical applications of hydroxyapatite: a review. RSC Advances, 2017, 7(13): 7442-7458.

[7] CHEN F, ZHU Y J. Multifunctional calcium phosphate nanostructured materials and biomedical applications. Current Nanoscience, 2014, 10(4): 465-485.

[8] ZHANG Y G, ZHU Y J, CHEN F, et al. A novel composite scaffold comprising ultralong hydroxyapatite microtubes and chitosan: preparation and application in drug delivery. Journal of Materials Chemistry B, 2017, 5(21): 3898-3906.

[9] CHEN F, ZHU Y J. Microwave-assisted synthesis of calcium phosphate nanostructured materials in liquid phase. Progress in Chemistry, 2015, 27(5): 459-471.

[10] YU Y D, ZHU Y J, QI C, et al. Hydroxyapatite nanorod-assembled hierarchical microflowers: rapid synthesis via microwave hydrothermal transformation of $\mathrm{CaHPO}_{4}$ and their application in protein/ drug delivery. Ceramics International, 2017, 43(8): 6511-6518.

[11] SUN T W, YU W L, ZHU Y J, et al. Porous nanocomposite comprising ultralong hydroxyapatite nanowires decorated with zinccontaining nanoparticles and chitosan: synthesis and application in bone defect repair. Chemistry - A European Journal, 2018, 24(35): 8809-8821.

[12] LU B Q, ZHU Y J, CHEN F. Highly flexible and nonflammable inorganic hydroxyapatite paper. Chemistry - A European Journal, 2014, 20(5): 1242-1246.

[13] ZHANG Y G, ZHU Y J, CHEN F, et al. Ultralong hydroxyapatite nanowires synthesized by solvothermal treatment using a series of phosphate sodium salts. Materials Letters, 2015, 144: 135-137.

[14] JIANG Y Y, ZHU Y J, CHEN F, et al. Solvothermal synthesis of submillimeter ultralong hydroxyapatite nanowires using calcium oleate precursor in a series of monohydroxy alcohols. Ceramics International, 2015, 41(4): 6098-6102.

[15] LI H, ZHU Y J, JIANG Y Y, et al. Hierarchical assembly of monodisperse hydroxyapatite nanowires and construction of highstrength fire-resistant inorganic paper with high-temperature flexibility. ChemNanoMat, 2017, 3(4): 259-268.

[16] DONG L Y, ZHU Y J. Fire-resistant inorganic analogous Xuan 
paper with thousands of years' super-durability. ACS Sustainable Chemistry Engineering, 2018, 6(12): 17239-17251.

[17] DONG L Y, ZHU Y J. A new kind of fireproof, flexible, inorganic, nanocomposite paper and its application to the protection layer in flame-retardant fiber-optic cables. Chemistry - A European Journal, 2017, 23(19): 4597-4604.

[18] LI H, WU D B, WU J, et al. Flexible, high-wettability and fireresistant separators based on hydroxyapatite nanowires for advanced lithium-ion batteries. Advanced Materials, 2017, 29(44): 1703548 .

[19] CHEN F F, ZHU Y J, CHEN F, et al. Fire alarm wallpaper based on fire-resistant hydroxyapatite nanowire inorganic paper and graphene oxide thermosensitive sensor. ACS Nano, 2018, 12(4): 3159-3171.

[20] SHAO Y T, ZHU Y J, DONG L Y, et al. A new kind of nanocomposite "Xuan paper" comprising ultralong hydroxyapatite nanowires and cellulose fibers with unique ink wetting performance. $R S C$ Advances, 2019, 9: 40750-40757.

[21] CHEN F, ZHU Y J, WANG K W, et al. Surfactant-free solvothermal synthesis of hydroxyapatite nanowire/nanotube ordered arrays with biomimetic structures. CrystEngComm, 2011, 13(6): 1858-1863.

[22] ZHAO X Y, ZHU Y J, CHEN F, et al. Hydrothermal synthesis of hydroxyapatite nanorods and nanowires using riboflavin-5'-phosphate monosodium salt as a new phosphorus source and their application in protein adsorption. CrystEngComm, 2013, 15(39): 7926-7935.

[23] BRAMHE S, KIM T N, BALAKRISHNAN A, et al. Conversion from biowaste venerupis clam shells to hydroxyapatite nanowires. Materials Letters, 2014, 135: 195-198.

[24] AI M, DU Z Y, ZHU S Q, et al. Composite resin reinforced with silver nanoparticles-laden hydroxyapatite nanowires for dental application. Dental Materials, 2017, 33(1): 12-22.

[25] HE J Y, ZHANG K S, WU S B, et al. Performance of novel hydroxyapatite nanowires in treatment of fluoride contaminated water. Journal of Hazardous Materials, 2016, 303(13): 119-130.
[26] QI C, TANG Q L, ZHU Y J, et al. Microwave-assisted hydrothermal rapid synthesis of hydroxyapatite nanowires using adenosine 5'-triphosphate disodium salt as phosphorus source. Materials Letters, 2012, 85: 71-73.

[27] LIN K L, LIU X G, CHANG J, et al. Facile synthesis of hydroxyapatite nanoparticles, nanowires and hollow nano-structured microspheres using similar structured hard-precursors. Nanoscale, 2011, 3(8): 3052-3055.

[28] YANG Z, HUANG Y, CHEN S T, et al. Template synthesis of highly ordered hydroxyapatite nanowire arrays. Journal of Materials Science, 2005, 40(5): 1121-1125.

[29] COSTA D O, DIXON S J, RIZKALLA A S. One- and three-dimensional growth of hydroxyapatite nanowires during Sol-Gel-hydrothermal synthesis. ACS Applied Materials \& Interfaces, 2012, 4(3): $1490-1499$.

[30] CAO M H, WANG Y H, GUO C X, et al. Preparation of ultrahighaspect-ratio hydroxyapatite nanofibers in reverse micelles under hydrothermal conditions. Langmuir, 2004, 20(11): 4784-4786.

[31] GANDHI M R, KOUSALYA G N, MEENAKSHI S. Removal of copper (II) using chitin/chitosan nano-hydroxyapatite composite. International Journal of Biological Macromolecules, 2011, 48(1): 119-124.

[32] MA M G, ZHU J F. Solvothermal synthesis and characterization of hierarchically nanostructured hydroxyapatite hollow spheres. European Journal of Inorganic Chemistry, 2009, 2009(36): 5522-5526.

[33] ZHANG Q Q, ZHU Y J, WU J, et al. Ultralong hydroxyapatite nanowire-based filter paper for high-performance water purification. ACS Applied Materials \& Interfaces, 2019, 11(4): 4288-4301.

[34] REHMAN I, BONFIELD W. Characterization of hydroxyapatite and carbonated apatite by photo acoustic FT-IR spectroscopy. Journal of Materials Science: Materials in Medicine, 1997, 8(1): 1-4.

[35] DEROCHE I, DAOU T J, PICARD C, et al. Reminiscent capillarity in subnanopores. Nature Communications, 2019, 10: 4642.

\title{
羟基磷灰石超长纳米线/植物纤维纳米复合 “宣纸”及其防霉性能
}

\author{
郡悦婷 ${ }^{1,2}$, 朱英杰 ${ }^{1,2}$, 董丽颖 ${ }^{1}$, 蔡安勇 ${ }^{1,2}$ \\ (1. 中国科学院 上海硅酸盐研究所, 上海 200050; 2. 中国科学院大学 材料与光电研究中心, 北京 100049)
}

摘 要: 宣纸是中国书画作品必不可少的载体，具有优良的耐久性和防霉性能，因此赢得了“纸中之王”的美誉。2009 年，宣纸被联合国教科文组织列入 《人类非物质文化遗产代表作名录》。差基磷灰石具有优良的生物相容性，环境 友好，白度高，是一种具有良好应用前景的生物材料。羟基磷灰石超长纳米线具有高柔韧性，可用于构建具有不同 功能的新型耐火纸。本研究发展了一种新型纳米复合“宣纸”, 由羟基磷灰石超长纳米线和植物纤维复合制成。所制 备的纳米复合“宣纸”的白度随着羟基磷灰石超长纳米线含量增加而得到提高, 当羟基磷灰石超长纳米线重量比为 $25 \%$ 时, 其白度为 $76.1 \%$, 高于商品生宣纸 $(71.9 \%$ )或商品熟宣纸(70.3\%)。采用三种霉菌(球毛壳霉菌、长枝木霉菌、 黑曲霉菌)研究了新型纳米复合“宣纸”的抗霉菌性能。实验结果显示，与传统宣纸相比，所制备的纳米复合“宣纸” 的防霉性能得到显著改善，与空白样品和商品宣纸相比，纳米复合“宣纸”对霉菌的生长具有更好的抑制能力，在其 表面三种霸菌的生长速率明显较低, 并且随着羟基磷灰石超长纳米线含量的增加而降低。在恒温恒湿箱内培养过程 中, 商品宣纸表面生长出霉菌, 但是纳米复合“宣纸”表面上没有观察到明显的霉菌生长。预期所制备的纳米复合 “宣纸”有助于书画艺术品的长久安全保存，在书法和绘画艺术中具有良好的应用前景。

关 键 词: 宣纸; 羟基磷灰石; 纳米线; 防霉

中图分类号: TQ174 文献标识码: A 